\title{
Selective synthesis of pure cobalt disulfide on reduced graphene oxide sheets and its high electrocatalytic activity for hydrogen evolution reaction
}

\author{
Seongjoon Ahn ${ }^{2,3+}$, Jieun Yang ${ }^{5 \dagger}$, Hyunseob Lim ${ }^{1,3,4}$ and Hyeon Suk Shin 1,23,4*
}

\begin{abstract}
We synthesized single-phase $\mathrm{CoS}_{2}$ on a large scale by adding graphene oxide of sufficient quantity via the hydrothermal method using cobalt acetate and thioacetamide as precursors; this produced the hybrid of $\mathrm{CoS}_{2}$ with reduced graphene oxide which exhibited high electrocatalytic activity in the hydrogen evolution reaction.
\end{abstract}

Keywords: Transition metal dichalcogenides, Cobalt disulfide, Hybrid, Electrocatalyst, Hydrogen evolution reaction

\section{Introduction}

Considerable efforts have been made toward synthesizing transition metal dichalcogenide (TMD) nanomaterials due to their excellent electronic, optical, and mechanical properties [1, 2]. Among the more notable TMD compounds, $\mathrm{MoS}_{2}$ and $\mathrm{WS}_{2}$, which have electrical properties that can be changed from metallic to semiconducting by varying their crystal structure and the number of layers, have been extensively studied [1]. In addition, the structure and general properties of pyrite-phase TMDs $\left(\mathrm{FeS}_{2}, \mathrm{NiS}_{2}\right.$, and $\left.\mathrm{CoS}_{2}\right)$ have been investigated [3-6]. These materials have attracted interest for their potential applications; for example, $\mathrm{FeS}_{2}$ with a band gap of $0.95 \mathrm{eV}$ has been used as an active layer in photovoltaic devices and $\mathrm{NiS}_{2}$ has been used as a $\mathrm{Li}$ storage material [6-9]. In particular, $\mathrm{CoS}_{2}$ has received considerable attention due to its metallic behavior, which makes it applicable as an electrocatalyst for oxygen reduction reactions and hydrogen evolution reactions (HERs) $[3,10,11]$.

So far, $\mathrm{MoS}_{2}$ and $\mathrm{WS}_{2}$ nanostructures have been extensively explored as electrocatalysts for HER. The overpotentials of $\mathrm{MoS}_{2}$ and $\mathrm{WS}_{2}$ materials occur between -200

\footnotetext{
*Correspondence: shin@unist.ac.kr; shin@snu.ac.kr

†'Seongjoon Ahn and Jieun Yang contributed equally to this work ${ }^{1}$ Department of Chemistry, Ulsan National Institute of Science and Technology (UNIST), UNIST-gil 50, Ulsan 689-798, Republic of Korea Full list of author information is available at the end of the article
}

and $-150 \mathrm{mV}$ and their Tafel slopes fall in the range of 55-40 and 70-58 mV/dec, respectively [2, 12]. Recently, metallic $\mathrm{CoS}_{2}$ has been recognized for its potential as a viable HER catalyst like $\mathrm{MoS}_{2}$. An overpotential of $-180 \mathrm{mV}$ and a Tafel slope of $44.6 \mathrm{mV} / \mathrm{dec}$ have been measured for $\mathrm{CoS}_{2}$ films synthesized by gas-phase reactions [3]. $\mathrm{CoS}_{2}$ micro- and nanowires have overpotentials of about -100 and $-70 \mathrm{mV}$, respectively, and Tafel slopes of 58.0 and $51.6 \mathrm{mV} / \mathrm{dec}$, respectively [10]. However, $\mathrm{CoS}_{2}$ film is easily damaged by delamination during $\mathrm{H}_{2}$ evolution. Although $\mathrm{CoS}_{2}$ nanowires exhibited the best performance, they became delaminated within three hours. Accounting for a long-term stability, microwires have proven the most effective, despite their limited HER performance. The microstructured surface also helps to convey the $\mathrm{H}_{2}$ bubbles away from the electrode surface, thus maintaining the integrity of the catalyst for HER [10]. On the other hand, the strong performance of $\mathrm{CoS}_{2}$ in HER may result from the oxidation state of sulfur in $\mathrm{CoS}_{2}$, since it is known that $\mathrm{S}_{2}{ }^{2-}$ exhibits higher HER efficiency than $\mathrm{S}^{2-}$. Chang et al. prepared $\mathrm{MoS}_{\mathrm{x}}$ with $\mathrm{S}_{2}{ }^{2-}$ on $3 \mathrm{D} \mathrm{Ni}$ foam deposited with graphene layers for electrocatalytic hydrogen evolution and found that $\mathrm{MoS}_{\mathrm{x}}$ with $\mathrm{S}_{2}{ }^{2-}$ exhibits higher catalytic activity than $\mathrm{MoS}_{2}$ with $\mathrm{S}^{2-}[13,14]$. Therefore, the HER activity of pure-phase $\mathrm{CoS}_{2}$ should be investigated since it is expected that $\mathrm{CoS}_{2}$ with $\mathrm{S}_{2}{ }^{2-}$ dimer

\section{量 Springer}

(c) 2016 Ahn et al. This article is distributed under the terms of the Creative Commons Attribution 4.0 International License (http://creativecommons.org/licenses/by/4.0/), which permits unrestricted use, distribution, and reproduction in any medium, provided you give appropriate credit to the original author(s) and the source, provide a link to the Creative Commons license, and indicate if changes were made. 
will exhibit favorable performance in HER. As mentioned above, pure-phase $\mathrm{CoS}_{2}$ nanowires and microwires were obtained by the synthesis of cobalt hydroxide carbonate hydrate $\left(\mathrm{Co}(\mathrm{OH})\left(\mathrm{CO}_{3}\right) 0.5 \cdot x \mathrm{H} 2 \mathrm{O}\right)$ nanowires and cobalt hydroxide $\left(-\mathrm{Co}(\mathrm{OH})_{2}\right)$ microwires through a solutionbased reaction followed by thermal sulfurization [10]. Additionally, pure-phase $\mathrm{CoS}_{2}$ film has been synthesized by sulfurization of Co film: The substrate on which Co is deposited by an e-beam evaporator is located in the tube furnace and sulfur powder is vaporized by flowing Ar gas at $550{ }^{\circ} \mathrm{C}$ [3]. All of the methods are two-step processes, which are limited in terms of mass production. Therefore, it would be worthwhile to establish a method for the large-scale synthesis of pure $\mathrm{CoS}_{2}$.

The hydrothermal reaction is known as a facile method for the large-scale synthesis of $\mathrm{CoS}_{2}$. However, producing pure-phase $\mathrm{CoS}_{2}$ is quite difficult because of the complex stoichiometric compositions of cobalt sulfides such as $\mathrm{CoS}_{2}, \mathrm{CoS}, \mathrm{Co}_{9} \mathrm{~S}_{8}$, and $\mathrm{Co}_{1-\mathrm{x}} \mathrm{S}$ that form when the hydrothermal synthesis of $\mathrm{CoS}_{2}$ is attempted using precursors such as cobalt chloride (as cobalt precursor) and thioacetamide, sodium thiosulfate, etc. (as sulfur precursors) [15-20]. Indeed, a mixture of cobalt sulfides has been synthesized using the hydrothermal method. For example, Huang et al. found that the flower-like cobalt sulfides prepared by a solvothermal method included a mixture of CoS and $\mathrm{Co}_{9} \mathrm{~S}_{8}(9 \%)$ [15]. Qian et al. then found that as-synthesized cobalt sulfides consisted of $\mathrm{CoS}_{2}, \mathrm{Co}_{9} \mathrm{~S}_{8}$, and $\mathrm{Co}_{3} \mathrm{~S}_{4}$ when using cobalt chloride in toluene [16]. Furthermore, most reports employed only X-ray diffraction (XRD) for the characterization of $\mathrm{CoS}_{2}$ [15-20]. However, in-depth characterization using TEM and XPS as well as XRD is required for the identification of $\mathrm{CoS}_{2}$, due to the existence of various stoichiometric compositions of cobalt sulfides. In addition, impurities such as oxygen can occur in $\mathrm{CoS}_{2}$ since it is susceptible to oxidation in air [10]. Thus, further research is required to allow for the characterization and large-scale production of pure $\mathrm{CoS}_{2}$ with $\mathrm{S}_{2}{ }^{2-}$ dimer.

Herein, we report on such a large-scale synthesis of pure-phase $\mathrm{CoS}_{2}$ on rGO by a one-pot hydrothermal reaction using cobalt acetate and thioacetamide precursors. We demonstrate that GO concentrations of greater than $2 \mathrm{mg} / \mathrm{mL}$ are critical in supporting the synthesis of pure-phase $\mathrm{CoS}_{2}$ and inhibiting the oxidation of the $\mathrm{CoS}_{2}$ surface. Furthermore, we provide detailed structural analyses of the synthesized $\mathrm{CoS}_{2}$ and investigate its electrocatalytic activity in HER, thereby demonstrating a long-term stability.

\section{Methods}

\subsection{Synthesis of GO solution}

GO was prepared from graphite powder by the modified Hummers' method.

\subsection{Hydrothermal synthesis of $\operatorname{CoS}_{2} / \mathrm{rGO}$ hybrid}

GO solution was added to the mixture of cobalt acetate tetrahydrate $(9 \mathrm{mmol})$ and thioacetamide $(90 \mathrm{mmol})$ and the total volume of the solution was adjusted to $400 \mathrm{~mL}$ for all reactions. The solution was transferred to a $500 \mathrm{~mL}$ Teflon-lined stainless steel autoclave, heated up to $240{ }^{\circ} \mathrm{C}$, and kept for $24 \mathrm{~h}$. After cooling naturally, the product was filtered, washed with DI water, and dried in vacuum at $60{ }^{\circ} \mathrm{C}$ for $12 \mathrm{~h}$. During the hydrothermal process, $\mathrm{GO}$ was converted to $\mathrm{rGO}$ and $\mathrm{CoS}_{2} / \mathrm{rGO}$ was formed.

\subsection{Characterization}

The samples were characterized with field emission scanning electron microscopy (Hitachi, S4800), high-resolution transmission electron microscopy (HRTEM, JEOL JEM-2100 F with probe-Cs corrector, $200 \mathrm{kV}$ ), X-ray diffraction [Rikgaku RU-200 diffractometer equipped with $\mathrm{Ni}$-filtered $\mathrm{Cu} \mathrm{K \alpha}$ radiation $(40 \mathrm{kV}, 100 \mathrm{~mA}$, $\lambda=0.15418 \mathrm{~nm})$ ], and X-ray photoelectron spectroscopy (K-alpha, ThermoFisherwith monochromatic Al $\mathrm{K} \alpha$ radiation as the $\mathrm{X}$-ray source). The $\mathrm{rGO}$ concentration of samples was characterized with element analyzer (Thermo Scientific, Flash 2000).

\subsection{Electrochemical measurements}

Electrocatalytic measurements were carried out using a 3-electrode cell and a $0.5 \mathrm{M}$ sulfuric acid $\left(\mathrm{H}_{2} \mathrm{SO}_{4}\right)$ electrolyte solution. A graphite rod (Sigma Aldrich) and Ag/ $\mathrm{AgCl}$ electrode (Wonatech) were used as counter electrode and reference respectively. The reference electrode was calibrated with respect to reversible hydrogen electrode (RHE) using platinum wires as working and counter electrodes. Materials were dispersed in deionized water at $4 \mathrm{mg} / \mathrm{mL}$ and sonicated for $1 \mathrm{~h}$. The ink was then drop-casted onto glassy carbon electrodes of $3 \mathrm{~mm}$ diameters (loading $285 \mu \mathrm{g} / \mathrm{cm}^{2}$ ) and capped by Nafion (0.5 \%, $3 \mu \mathrm{L}$, Sigma Aldrich). Linear sweep voltammetry was performed with a $5 \mathrm{mV} / \mathrm{s}$ scan rate using a Zive SP2 potentiostat from Wonatech and the electrodes were cycled at least 40 cycles prior to any measurement. The polarization curves were iR-corrected. Electrochemical impedance spectroscopy (EIS) was performed in the frequency range from $1 \mathrm{MHz}$ to $0.1 \mathrm{~Hz}$.

\section{Results and discussion}

In a typical hydrothermal reaction with $\mathrm{CoS}_{2}$, cobalt precursor such as cobalt chloride reacts with thioacetamide, sodium thiosulfate, etc. to produce $\mathrm{CoS}_{2}$ [15-20]. However, the problem with this method involves the generation of impurities such as $\mathrm{Co}_{3} \mathrm{~S}_{4}$ and $\mathrm{Co}_{9} \mathrm{~S}_{8}$ along with $\mathrm{CoS}_{2}$, even though they occur in small proportions $[15$, 16]. Although there are some reports on the synthesis of 
$\mathrm{CoS}_{2} / \mathrm{rGO}$, synthesis of pure $\mathrm{CoS}_{2}$ on rGO sheets has not been clearly demonstrated. It should be noted that these preliminary studies employed small amounts of GO, less than $1 \mathrm{mg} / \mathrm{mL}$, in final reactant solutions for hydrothermal reactions $[11,15,18-21]$. Note that growth condition for other reported cobalt sulfide/rGO material is summarized in Additional file 1: Table S1. In this study, we produced pure $\mathrm{CoS}_{2}$ on rGO sheets using GO concentrations of greater than $2 \mathrm{mg} / \mathrm{mL}$. Specifically, we carried out hydrothermal reactions at different concentrations of $\mathrm{GO}(0.2,1,1.6,2,2.3,2.6$, and $4 \mathrm{mg} / \mathrm{mL})$ in the synthesis of pure $\mathrm{CoS}_{2}$ (Table 1). Moreover, cobalt acetate tetrahydrate was used as a precursor for Co because it is known that cobalt acetate yields smaller crystal sizes and higher-BET surfaces than cobalt chloride [22, 23]. Each hydrothermal reaction was carried out at $240{ }^{\circ} \mathrm{C}$ for $24 \mathrm{~h}$ using cobalt acetate tetrahydrate, thioacetamide (TAA), and GO, followed by a washing of the product with distilled water and drying in vacuum at $60{ }^{\circ} \mathrm{C}$. It is noted that $240{ }^{\circ} \mathrm{C}$ was determined to be an optimum temperature from experimental results performed at various temperatures (Additional file 1: Figure S1). For reference, the weight percentage of $\mathrm{rGO}$ in some final products is provided in Additional file 1: Table S2. As a control experiment, hydrothermal reaction was also performed without GO, producing a mixture of $\mathrm{Co}_{3} \mathrm{~S}_{4}, \mathrm{CoS}$, and $\mathrm{CoS}_{2}$ (see the XRD data in Fig. 1a below). Interestingly, a hybrid of pure $\mathrm{CoS}_{2}$ and $\mathrm{rGO}\left(\mathrm{CoS}_{2} / \mathrm{rGO}\right)$ was obtained when more than $2 \mathrm{mg} / \mathrm{mL}$ of $\mathrm{GO}$ was added. It is worth noting that $\mathrm{GO}$ is partially reduced during reaction, meaning that the product is $\mathrm{CoS}_{2} / \mathrm{rGO}$. Actually, $\mathrm{Co}^{2+}$ ions can be linked into the functional groups of GO sheets to form strong $\mathrm{Co}^{2+}$-linked GO cylinders [24].

Consequently, it is expected that these cobalt ions are protected from unexpected reaction, meaning that $\mathrm{CoS}_{2}$ on rGO is produced, whereas free cobalt ions undergo unwanted reactions during hydrothermal reaction to yield

\section{Table 1 Experimental conditions for $\operatorname{CoS}_{2} / \mathrm{rGO}$ synthesis} with various concentrations of $\mathrm{GO}$

\begin{tabular}{lll}
\hline $\begin{array}{l}\text { Concentration of GO } \\
(\mathbf{m g} / \mathbf{m L})\end{array}$ & $\begin{array}{l}\text { Ratio of GO: } \\
\text { (mg:mmol) }\end{array}$ & \\
\hline 0 & $0: 1$ & $\mathrm{CoS}_{2}+\mathrm{Co}_{3} \mathrm{~S}_{4}+\mathrm{Co}_{3} \mathrm{O}_{4}+\mathrm{CoS}$ \\
0.2 & $8.8: 1$ & $\mathrm{CoS}_{2}+\mathrm{Co}_{3} \mathrm{~S}_{4}+\mathrm{CoS}$ \\
1 & $44: 1$ & $\mathrm{CoS}_{2}+\mathrm{CoS}$ \\
1.6 & $70.4: 1$ & $\mathrm{CoS}_{2}+\mathrm{CoS}$ \\
2 & $88: 1$ & $\mathrm{CoS}_{2}$ \\
2.3 & $101.2: 1$ & $\mathrm{CoS}_{2}$ \\
2.6 & $114.4: 1$ & $\mathrm{CoS}_{2}$ \\
4 & $176: 1$ & $\mathrm{CoS}_{2}$ \\
\hline
\end{tabular}

$\mathrm{Co}_{3} \mathrm{~S}_{4}, \mathrm{Co}_{9} \mathrm{~S}_{8}$, and other cobalt sulfides. Furthermore, rGO sheets play a role as an oxidation-resistance layer for cobalt sulfides. $\mathrm{CoS}_{0}$ covered by rGO was not oxidized, while $\mathrm{Co}_{3} \mathrm{~S}_{4}$ obtained without $\mathrm{GO}$ became oxidized to $\mathrm{Co}_{3} \mathrm{O}_{4}$. It is generally known that cobalt sulfides are easily oxidized in air (See the XPS data in Fig. 2 below) [10]. These results are supported by a previous report on the oxidation resistance of multilayer rGO [25]. Since dimeric $\mathrm{S}_{2}{ }^{2-}$ in $\mathrm{VS}_{4}$ can be obtained on graphitic layers, such as those in $\mathrm{rGO}$ and carbon nanotubes [26], the formation of pure $\mathrm{CoS}_{2}$ on rGO sheets is not unexpected.

Scanning electron microscopy (SEM) images of $\mathrm{CoS}_{2} /$ rGO with different concentrations of GO and a mixture of cobalt sulfides without GO are shown in Fig. 3. In the absence of GO, an aggregation of particles occurred (Fig. 3a and the TEM images in Additional file 1: Figure S2). On the other hand, $\mathrm{CoS}_{2}$ nanoparticles were covered by the rGO sheets for GO concentrations of 1 and $2.3 \mathrm{mg} / \mathrm{mL}$ (Fig. 3b, c). The transmission electron microscopy (TEM) images also demonstrate the growth of single-crystalline $\mathrm{CoS}_{2}$ nanoparticles on the rGO sheets (Fig. 3d, e). Figure 3e shows the rGO sheets with an interlayer $\mathrm{d}$-spacing of $0.34 \mathrm{~nm}$, which corresponds to the $\mathrm{d}$-spacing of graphite, surrounding the $\mathrm{CoS}_{2}$. Figure 3f shows $\mathrm{CoS}_{2}$ nanoparticles with a d-spacing of $0.25 \mathrm{~nm}$, which corresponds to the inter-planar spacing of the (210) plane of the cubic phase. In addition, the SAED pattern establishes the single-crystalline nature of the $\mathrm{CoS}_{2}$ particles (inset of Fig. 3f). To identify the stoichiometry of Co and S, an elemental mapping of the $\mathrm{CoS}_{2} / \mathrm{rGO}$ hybrids was performed via energy-dispersive X-ray spectroscopy (EDX); this mapping indicated that the ratio of $\mathrm{S}$ to Co was 2 (Additional file 1: Figure S3). Note that the $\mathrm{C}$ and $\mathrm{O}$ in the EDX spectrum are attributed to the rGO.

Figure 1a shows the X-ray diffraction (XRD) spectra of the products according to GO concentration. When $\mathrm{GO}$ is not added, there are not only reflections of $\mathrm{CoS}_{2}$ such as the (200), (220), and (311) planes, but also reflections for $\mathrm{CoS}, \mathrm{Co}_{3} \mathrm{~S}_{4}$, and $\mathrm{Co}_{3} \mathrm{O}_{4}$. This result is in good agreement with previous reports stating that multiphase cobalt sulfides are usually synthesized in these conditions $[15,16]$. Note that $\mathrm{CoS}$ was partially observed along with $\mathrm{CoS}_{2}$ for a $1 \mathrm{mg} / \mathrm{mL}$ GO concentration (Fig. 1a, JCPDS 75-0605). This result is consistent with the TEM results, which indicate a d-spacing corresponding to the (100) plane of hexagonal-phase $\mathrm{CoS}$ within the $\mathrm{CoS}_{2} / \mathrm{rGO}$ products (Additional file 1: Figure S4, space group P63/ mmc; $\mathrm{a}=3.384 \AA, \mathrm{c}=5.16 \AA$ ). In addition, our XRD pattern for $\mathrm{CoS}_{2} / \mathrm{rGO}$ did not show signs of oxidation, while the non-GO $\mathrm{Co}_{3} \mathrm{~S}_{4}$ showed a pattern for $\mathrm{Co}_{3} \mathrm{O}_{4}$ (Fig. 1a, JCPDS 42-1448; JCPDS 80-1543). Furthermore, we calculated the average crystal size by Scherrer formula using the (200) plane. The results show $36.65 \mathrm{~nm}$ and $33.82 \mathrm{~nm}$ for the $\mathrm{CoS}_{2} / \mathrm{rGO}(2.3 \mathrm{mg} / \mathrm{mL})$ and $\mathrm{CoS}_{2} / \mathrm{rGO}(1 \mathrm{mg} /$ 

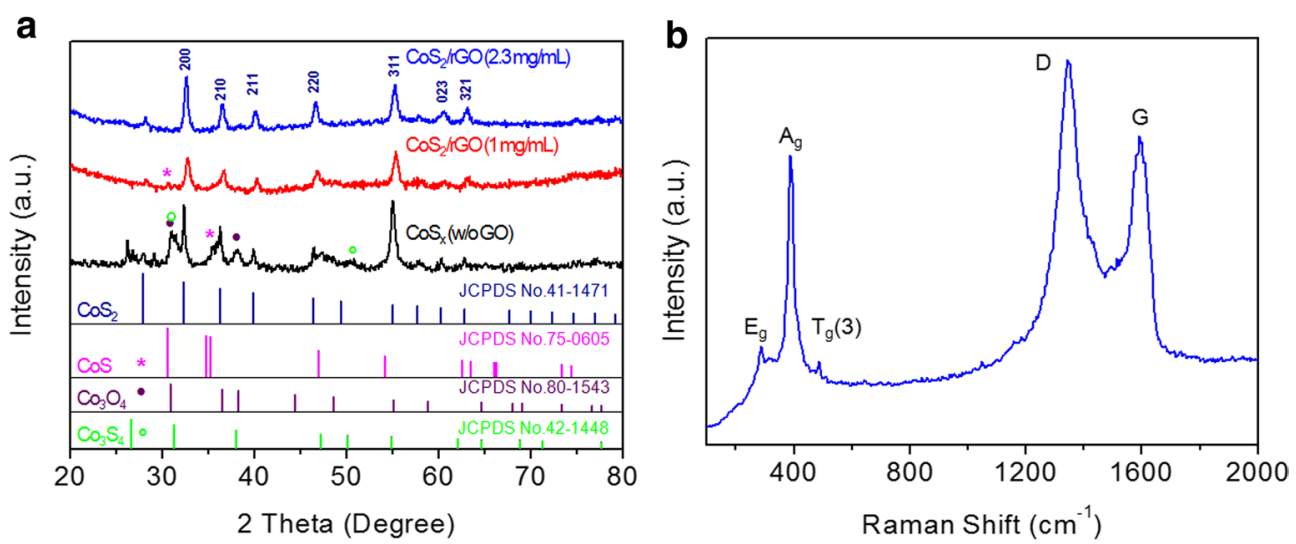

Fig. 1 a XRD patterns of $\mathrm{COS}_{2} / \mathrm{rGO}$. Cobalt sulfides without $\mathrm{GO}$ (black) and $\mathrm{CoS}_{2} / \mathrm{rGO}$ with $1 \mathrm{mg} / \mathrm{mL} \mathrm{GO}$ (red) and $2.3 \mathrm{mg} / \mathrm{mL} \mathrm{GO}$ (blue) compared with standard patterns for $\mathrm{CoS}_{2}$ (navy lines), $\mathrm{CoS}$ (pink lines), $\mathrm{Co}_{3} \mathrm{~S}_{4}$ (green lines), and $\mathrm{CO}_{3} \mathrm{O}_{4}$ (violet lines). b Raman spectrum of $\mathrm{CoS}_{2} / \mathrm{rGO}$ with $2.3 \mathrm{mg} /$ $\mathrm{mL} \mathrm{GO}$

a Co $2 p$

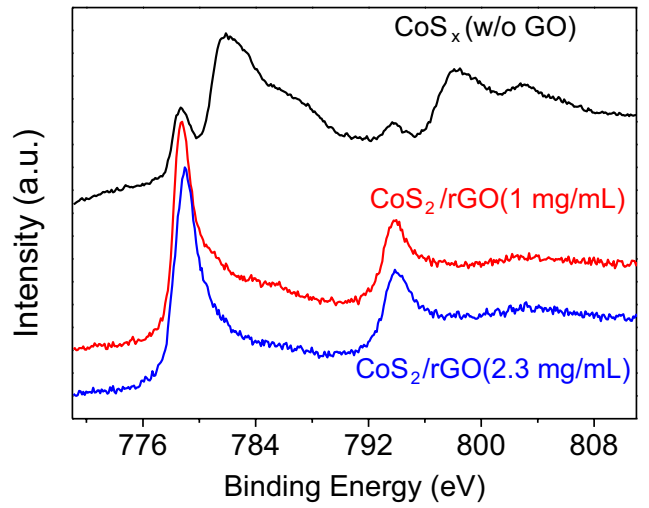

b $S 2 p$

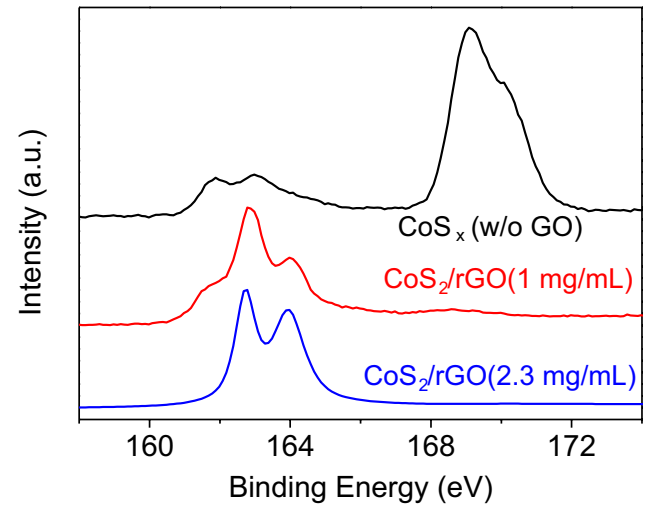

Fig. 2 X-ray photoelectron spectra of the $\mathbf{a} \mathrm{Co} 2 \mathrm{p}$ and $\mathbf{b} \mathrm{S} 2 \mathrm{p}$ regions for $\mathrm{CoS}_{2}$ without $\mathrm{GO}$ (black) and for $\mathrm{CoS}_{2} / \mathrm{rGO}$ with $1 \mathrm{mg} / \mathrm{mL} \mathrm{GO}$ (red) and $2.3 \mathrm{mg} / \mathrm{mL} \mathrm{GO}$ (b/ue)

$\mathrm{mL}$ ), respectively. These results are well matched with the SEM data in Fig. 3. Note that XRD spectra for $\mathrm{CoS}_{2} /$ rGO samples with various GO concentrations in Table 1 are shown in Additional file 1: Figure S5 and pure-phase $\mathrm{CoS}_{2}$ was obtained when GO concentration is higher than $2 \mathrm{mg} / \mathrm{mL}$. A representative Raman spectrum of $\mathrm{CoS}_{2} / \mathrm{rGO}(2.3 \mathrm{mg} / \mathrm{mL}$ of GO) is shown in Fig. 1b. Characteristic peaks for $\mathrm{CoS}_{2}$ at 288, 388, and $484 \mathrm{~cm}^{-1}$ corresponding to the $E_{g}, A_{g}$, and $T_{g}(3)$ modes, respectively [27], and the $\mathrm{D}$ and $\mathrm{G}$ bands of rGO, can be clearly seen.

To verify the oxidation states of the elements in the $\mathrm{CoS}_{2} / \mathrm{rGO}$ products, we measured their X-ray photoelectron spectroscopy (XPS) spectra (Fig. 2). The peaks for the binding energy of Co $2 \mathrm{p}_{3 / 2-1 / 2}$ appeared at 778.8 and $794 \mathrm{eV}$ for the $\mathrm{CoS}_{2} / \mathrm{rGO}$ sample with $1 \mathrm{mg} / \mathrm{mL}$ GO and at 779 and $794.2 \mathrm{eV}$ for the sample with $2.3 \mathrm{mg} / \mathrm{mL}$ GO, indicating an oxidation state of $\mathrm{Co}^{2+}$ (Fig. 2a) [10].
The peaks around 786 and $803 \mathrm{eV}$ are associated with the shake-up type peaks of the $2 \mathrm{p}_{3 / 2-1 / 2}$ and peaks at 782.3 and $798 \mathrm{eV}$ are associated with $\mathrm{Co}^{3+}$ from the mixture of cobalt sulfides without GO [28]. For the case of $S 2 p_{3 / 2-1 / 2}$, doublet peaks appear at 162.9 and $164 \mathrm{eV}$ for the $\mathrm{CoS}_{2} /$ rGO with $1 \mathrm{mg} / \mathrm{mL} \mathrm{GO}$ sample and at 162.6 and $163.9 \mathrm{eV}$ for the $\mathrm{CoS}_{2} / \mathrm{rGO}$ with $2.3 \mathrm{mg} / \mathrm{mL}$ GO sample, indicating the presence of $\mathrm{S}_{2}{ }^{2-}$ (Fig. 2b) [10]. Note that there is an additional peak at $\sim 161.8 \mathrm{eV}$ for $\mathrm{S}^{2-}$ in the $\mathrm{CoS}_{2} / \mathrm{rGO}$ with $1 \mathrm{mg} / \mathrm{mL}$ GO sample and cobalt sulfides without rGO [29]. Although $\mathrm{CoS}_{2}$ is easily oxidized in air as mentioned above [10], our results show no peak for oxidation in any of the $\mathrm{CoS}_{2} / \mathrm{rGO}$ samples, while there is a substantial oxidation peak at $169.1 \mathrm{eV}$ for the non-GO sample in Fig. $2 b$, which is consistent with the XRD spectra. Consequently, the XPS results confirm the pure-phase nature of the $\mathrm{CoS}_{2}$ for $\mathrm{GO}$ concentration of $2.3 \mathrm{mg} / \mathrm{mL}$. 

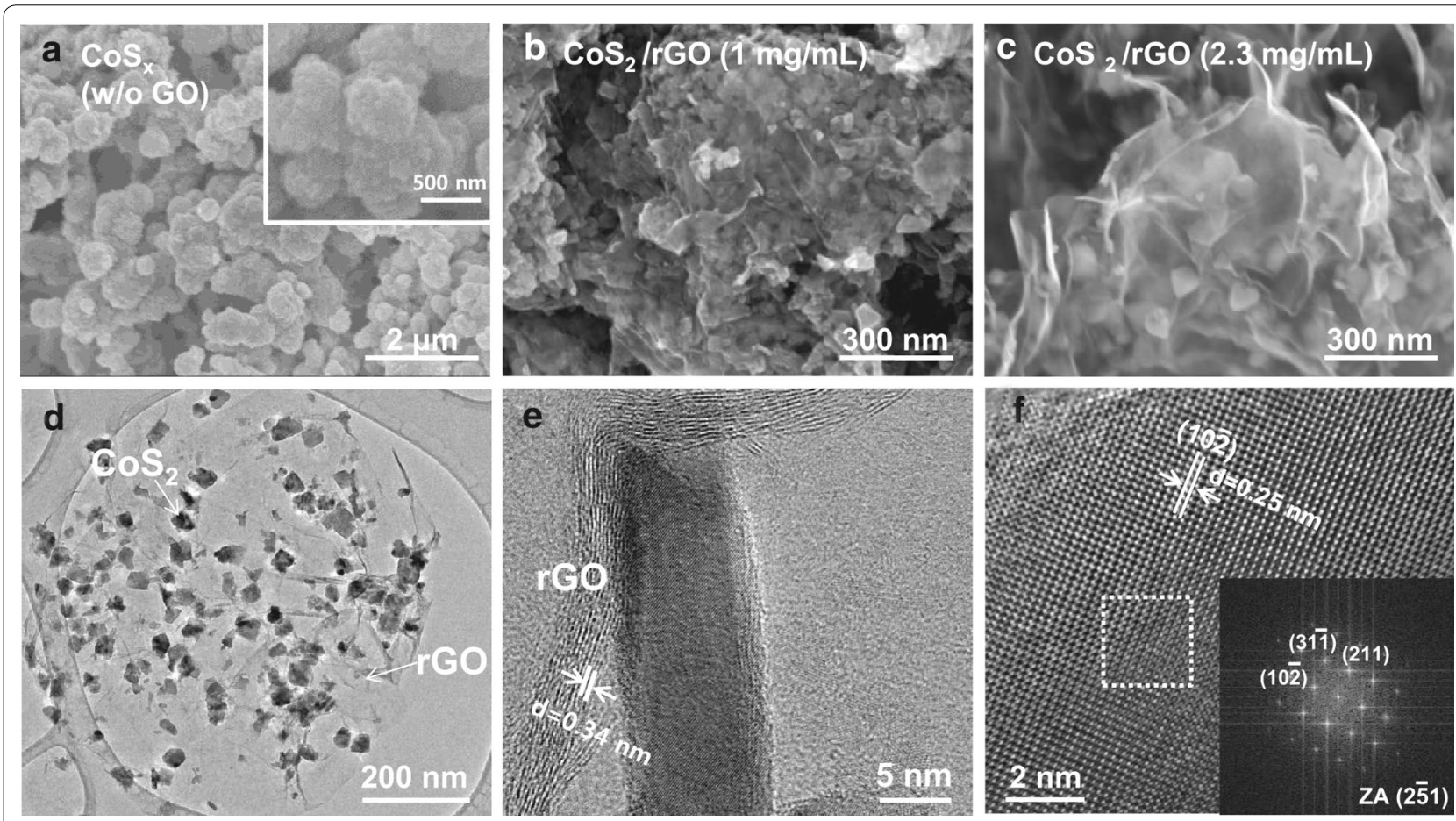

Fig. 3 SEM images of $\mathrm{CoS}_{2}$ particles a without $\mathrm{GO}$, b with $1 \mathrm{mg} / \mathrm{mL} \mathrm{GO}$, and $\mathbf{c}$ with $2.3 \mathrm{mg} / \mathrm{mL} \mathrm{GO}$. d Low magnification TEM image of CoS $/ \mathrm{rGO}$ with $2.3 \mathrm{mg} / \mathrm{mL}$ GO. e An enlarged TEM image of $\mathrm{CoS}_{2} / \mathrm{rGO}$ and $\mathbf{f}$ a high resolution TEM image of $\mathrm{CoS}_{2}$, the latter showing $\mathrm{d}$-spacing of $0.27 \mathrm{~nm}$ in the (200) plane. The inset in $\mathbf{f}$ provides a diffraction pattern of the $\mathrm{CoS}_{2}$ in the white square

To explore practical viability, HER tests with the $\mathrm{CoS}_{2} /$ rGO samples on glassy carbon electrodes were carried out using a three-electrode cell with a $0.5 \mathrm{M}$ sulfuric acid electrolyte. Polarization curves (I-V plots) were taken for $\mathrm{CoS}_{2} / \mathrm{rGO}$ samples ( 1 and $2.3 \mathrm{mg} / \mathrm{mL} \mathrm{GO}$ ) along with a mixture of cobalt sulfides without GO (Fig. 4a). The overpotential of the 2.3 and $1 \mathrm{mg} / \mathrm{mL} \mathrm{GO}$ samples were found to be -150 and $-180 \mathrm{mV}$ versus RHE, respectively. The overpotentials required to drive current densities of $10 \mathrm{~mA} / \mathrm{cm}^{2}$ were $228 \mathrm{mV}$ for the $2.3 \mathrm{mg} / \mathrm{mL} \mathrm{GO}$ sample and $250 \mathrm{mV}$ for the $1 \mathrm{mg} / \mathrm{mL}$ GO sample. The mixture of cobalt sulfides without GO exhibited HER activity with an overpotential of $-280 \mathrm{mV}$ versus RHE. The Tafel plots derived from these data are shown in Fig. 4b wherein the linear portions were fitted to the Tafel equation to determine the slopes. The Tafel plots reveal a slope of $71 \mathrm{mV} /$ dec for the mixture of cobalt sulfides without GO, $55 \mathrm{mV} /$ dec for $\mathrm{CoS}_{2} / \mathrm{rGO}$ with $1 \mathrm{mg} / \mathrm{mL} \mathrm{GO}$, and $48 \mathrm{mV} / \mathrm{dec}$ for $\mathrm{CoS}_{2} / \mathrm{rGO}$ with $2.3 \mathrm{mg} / \mathrm{mL}$ GO. The lower Tafel slope value for the $\mathrm{CoS}_{2} / \mathrm{rGO}$ hybrid materials, compared to the non-GO sample, can be attributed to the contribution of $\mathrm{CoS}_{2}$ as an active material and the presence of conductive rGO. The pure-phase catalyst clearly plays a key role in revealing the intrinsic activity of $\mathrm{CoS}_{2}$, and the metallic property of $\mathrm{CoS}_{2}$ allows efficient charge transport from the electrode to the surface of the catalysts, which is desired for high-performance electrocatalysts [10]. It should also be noted that the impedance results indicate a lower resistance in the $\mathrm{CoS}_{2} / \mathrm{rGO}$ electrode with $2.3 \mathrm{mg} /$ $\mathrm{mL}$ GO than with $1 \mathrm{mg} / \mathrm{mL}$ GO (Fig. 4c). Thus, the formation of an interconnected conducting rGO network can facilitate rapid electron transfer from the electrode to the catalyst. This tendency that the $\mathrm{CoS}_{2} / \mathrm{rGO}$ electrode with $2.3 \mathrm{mg} / \mathrm{mL} \mathrm{GO}$ showed higher catalytic activity than that with $1 \mathrm{mg} / \mathrm{mL} \mathrm{GO}$ was also confirmed in the capacitive current for each $\mathrm{CoS}_{2}$ electrode as a function of scan rate which reveals the double layer capacitance (Additional file 1: Figure S6). The HER performance for the $\mathrm{CoS}_{2} / \mathrm{rGO}$ samples with various concentrations of GO was also measured (Additional file 1: Figure S7). Considering the onset potentials and Tafel slopes, we found that 2 and $2.3 \mathrm{mg} / \mathrm{mL}$ represent optimized concentrations of GO in terms of HER performance. With concentrations lower than $2.0 \mathrm{mg} / \mathrm{mL}, \mathrm{CoS}$ is partially included and resistance is relatively high. With $4 \mathrm{mg} / \mathrm{mL}, \mathrm{rGO}$ is expected to hinder the exposure of $\mathrm{CoS}_{2}$ as a catalyst, and the charge-transfer resistance of the $\mathrm{CoS}_{2} / \mathrm{rGO}$ sample increased slightly (Additional file 1: Figure S8). Recently, the performance of HER for $\mathrm{CoS}_{2}$ film (overpotential of $-180 \mathrm{mV}$ and Tafel slope of $44.6 \mathrm{mV} / \mathrm{dec}$ ) was reported [3]. Thus, the onset potential and Tafel slope values of $\mathrm{CoS} 2 / \mathrm{rGO}(2.3 \mathrm{mg} / \mathrm{mL} \mathrm{GO})$ are roughly commensurate 

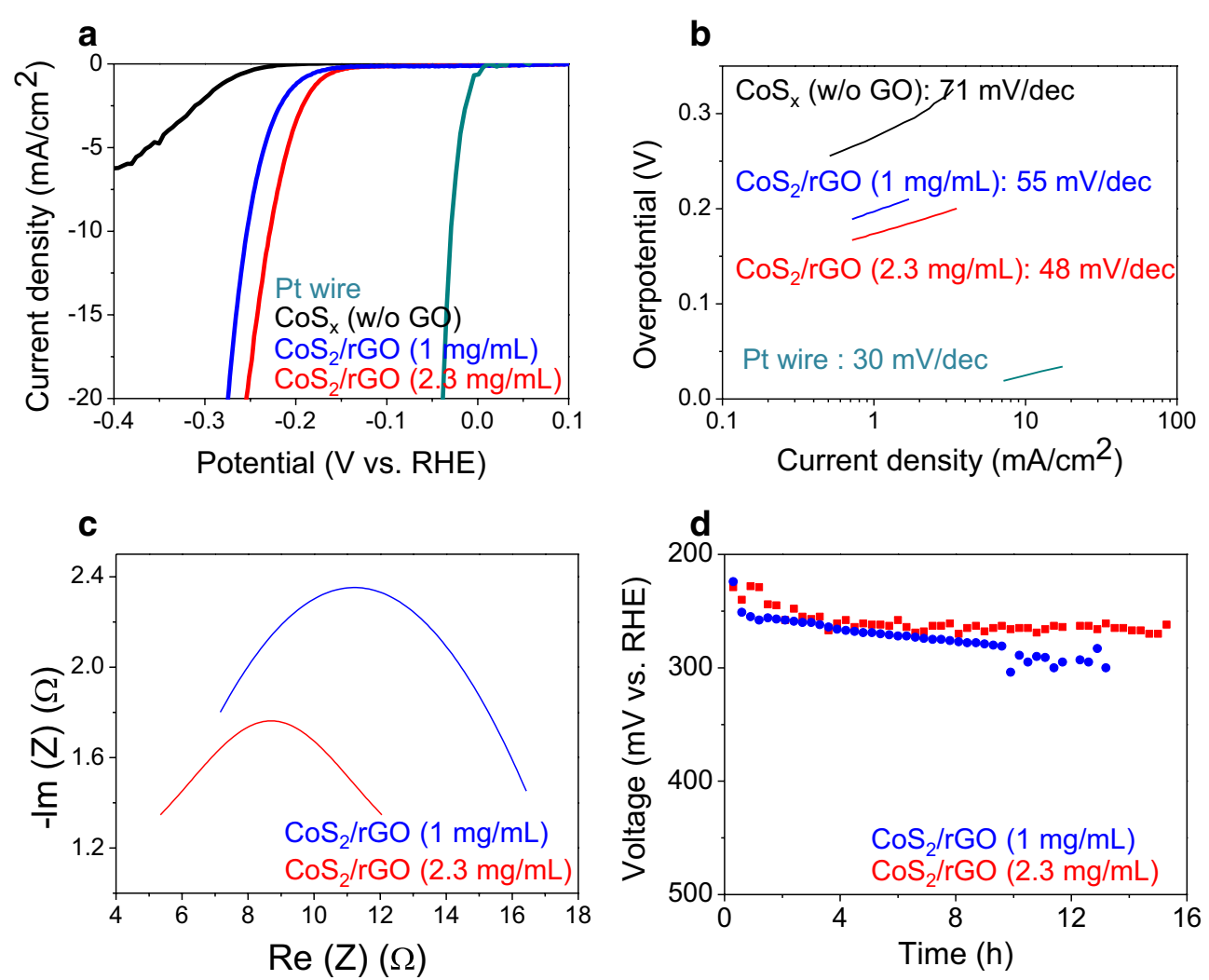

Fig. 4 Catalytic activity for hydrogen evolution reactions. a Polarization curves (iR-corrected) of Pt wires (green), the mixture of cobalt sulfide without GO (black), and $\mathrm{CoS}_{2} / \mathrm{rGO}$ samples with $1 \mathrm{mg} / \mathrm{mL} \mathrm{GO}$ (blue) and with $2.3 \mathrm{mg} / \mathrm{mL} \mathrm{GO}$ (red). b Tafel analysis of the data shown in a. c Electrochemical impedance spectroscopy (EIS) for $\mathrm{CoS}_{2} / \mathrm{rGO}$ samples. d Long-term stability measurements for $\mathrm{CoS}_{2} / \mathrm{rGO}$ samples

with those of the $\mathrm{CoS}_{2}$ film. However, our catalysts have an improved a long-term stability than that reported for the $\mathrm{CoS}_{2}$ film, which is relatively limited. That is, $\mathrm{CoS}_{2}$ films are known to become delaminated with a physical loss of catalysts occurring within $1 \mathrm{~h}$ during cycling. However, $\mathrm{CoS}_{2} / \mathrm{rGO}$ electrodes maintain hydrogen evolution at $\mathrm{J}_{\text {cathodic }}=10 \mathrm{~mA} / \mathrm{cm}^{2}$ with minimal change in the applied overpotential, as shown in Fig. 4d. It is noted that the phase and structure of $\mathrm{CoS}_{2} / \mathrm{rGO}$ maintained after the cycling for $14 \mathrm{~h}$ (Additional file 1: Figure S9). After $15 \mathrm{~h}$, the catalysts became delaminated. We summarize the HER performance for various $\mathrm{CoS}_{2}$ structures in the literature, including our results in Additional file 1: Table S3.

\section{Conclusions}

In summary, we successfully synthesized $\mathrm{CoS}_{2} / \mathrm{rGO}$ with pure-phase $\mathrm{CoS}_{2}$ on rGO sheets via hydrothermal reaction. The $\mathrm{CoS}_{2} / \mathrm{rGO}$ hybrid materials exhibited high catalytic activity for HER: overpotential of $-150 \mathrm{mV}$ versus RHE and a Tafel slope of $48 \mathrm{mV} / \mathrm{dec}$ for $\mathrm{CoS}_{2} / \mathrm{rGO}$ $(2.3 \mathrm{mg} / \mathrm{mL}$ GO). Thus, the present study demonstrates the large-scale synthesis of $\mathrm{CoS}_{2} / \mathrm{rGO}$ hybrids with a long-term stability and strong HER performance.

\section{Additional file}

Additional file 1: Figure S1. XRD patterns of CoS/rGO samples synthesized at different temperatures: 200 (black), 240 (red),and 265 C (blue). Figure S2. TEM image of cobalt sulfides without GO: (a) low magnification and (b) highmagnificationimages. The inset in (b) indicates the (111) diffraction pattern of $C o S$ in the white square. Figure S3. EDS elemental mapping of $C o$ and $S$ for CoS $/ \mathrm{rGO}(2.3 \mathrm{mg} / \mathrm{mL}$ of GO), EDX spectrum and tableshowing elemental composition. The atomic ratio of $\mathrm{S}$ and $\mathrm{Co}$ is 2, confirming the stoichiometry of $\mathrm{COS}$. Figure S4. TEM image of COS $/ \mathrm{rGO}$ (1 mg/mL of GO). (a) Bright field TEM image in low magnification (b)High resolution TEM image of CoS particle. (c) High resolution TEM image of a $\mathrm{COS}$ particle which is not covered by rGO. Inset of (b) shows planes of CoS including (311) plane and inset of (c) shows planes of CoS including (100) plane. Figure S5. XRD patterns of the CoS / rGO hybrids with various GO concentrations. Figure S6. (a) Plots for the extraction of the double-layer capacitance (C) for CoS/rGO electrodes. CV cycles of CoS /rGO samples with $1 \mathrm{mg} / \mathrm{mL}$ of $\mathrm{GO}$ (b) and $2.3 \mathrm{mg} / \mathrm{mL}$ of $\mathrm{GO}$ (c) at different scan rates. Figure S7. Polarization curves of $\mathrm{CoS} / \mathrm{rGO}$ depending on the concentration of $\mathrm{GO}$ at (a) higher and (b) lower applied oveportentials show the HER performance. (c) Tafel analysis of the data shown in Figure S5a. (d) Summary of the electrochemical performance for $\mathrm{CoS} / \mathrm{rGO}$ samples with various $\mathrm{GO}$ concentrations. Figure S8. Electrochemical impedance spectroscopy (EIS) for CoS $/ r G O$ samples. Figure S9. (a) SEM image of CoS $/ r G O(2.3 \mathrm{mg} / \mathrm{mL}$ of GO) after the cycling test for 14 hours. (b) High resolution TEM image of a COS particle after the cycling test. Inset of (b) shows planes of CoS including (102) plane. Table S1. Comparison of growth condition for $\mathrm{COS} / \mathrm{rGO}$ with other reported cobalt sulfide/ $\mathrm{rGO}$ materials. Table S2. The weight percentage of rGO in products by elemental analysis. Table S3. Comparison of HER activity measured for our CoS2/rGO with other reported CoS materials as HER catalyst. 


\section{Author details}

1 Department of Chemistry, Ulsan National Institute of Science and Technology (UNIST), UNIST-gil 50, Ulsan 689-798, Republic of Korea. ${ }^{2}$ Department of Energy Engineering, Ulsan National Institute of Science and Technology (UNIST), UNIST-gil 50, Ulsan 689-798, Republic of Korea. ${ }^{3}$ Low Dimensional Carbon Materials, Ulsan National Institute of Science and Technology (UNIST) UNIST-gil 50, Ulsan 689-798, Republic of Korea. ${ }^{4}$ Center for Multidimensional Carbon Materials, Institute of Basic Science, Ulsan National Institute of Science and Technology (UNIST), UNIST-gil 50, Ulsan 689-798, Republic of Korea.

${ }^{5}$ Department of Material Science and Engineering, Rutgers University, Piscataway, NJ 08854, USA.

\section{Acknowledgements}

This work was supported by the NRF Grant (NRF-2014R1A2A2A01007136) and a Grant (Code No. 2011-0031630) from the Center for Advanced Soft Electronics under the Global Frontier Research Program through the National Research Foundation funded by the Ministry of Science, ICT and Future Planning, Korea and by the framework of Indus-try Convergence Fundamental Technology Development Program (10050509, MOTIE, Korea) of Korea Evaluation Institute of Industrial Technology by the Ministry of Trade, Industry and Energy, Korea.

\section{Competing interests}

The authors declare that they have no competing interests.

Received: 16 September 2015 Accepted: 13 January 2016

Published online: 27 January 2016

\section{References}

1. Q.H. Wang, K. Kalantar-Zadeh, A. Kis, J.N. Coleman, M.S. Strano, Nat. Nanotechnol. 7, 699-712 (2012)

2. M. Chhowalla, H.S. Shin, G. Eda, L.-J. Li, K.P. Loh, H. Zhang, Nat. Chem. 5, 263 (2013)

3. D. Kong, J.J. Cha, H. Wang, H.R. Lee, Y. Cui, Energy Environ. Sci. 6 3553-3558 (2013)

4. D. Kong, H. Wang, Z. Lu, Y. Cui, J. Am. Chem. Soc. 136, 4897-4900 (2014)

5. D.-W. Wang, Q.-H. Wang, T.-M. Wang, CrystEngComm 12, 755-761 (2012)

6. J. Puthussery, S. Seefeld, N. Berry, M. Gibbs, M. Law, J. Am. Chem. Soc. 133 716-719 (2011)

7. R. Morrish, R. Silverstein, C.A. Wolden, J. Am. Chem. Soc. 134, 1785417857 (2012)
8. J.S. Jirkovsky, A. Bjorling, E. Ahlberg, J. Phys. Chem. C 116, 24436-24444 (2012)

9. Q. Wang, L. Jiao, Y. Han, H. Du, W. Peng, Q. Huan, D. Song, Y. Si, Y. Wang, H. Yuan, J. Phys. Chem. C 115, 8300-8304 (2011)

10. M.S. Faber, R. Dziedzic, M.A. Lukowski, N.S. Kaiser, Q. Ding, S. Jin, J. Am. Chem. Soc. 136, 10053-10061 (2014)

11. H. Wang, Y. Liang, Y. Li, H. Dai, Angew. Chem. Int. Ed. 50, 10969-10972 (2011)

12. J. Yang, H.S. Shin, J. Mater. Chem. A 2, 5979-5985 (2014)

13. Y.-H. Chang, C.-T. Lin, T.-Y. Chen, C.-L. Hsu, Y.-H. Lee, W. Zhang, K.-H. Wei, L.-J. Li, Adv. Mater. 25, 756-760 (2013)

14. Y.-H. Chang, F.-Y. Wu, T.-Y. Chen, C.-L. Hsu, C.-H. Chen, F. Wiryo, K.-H. Wei, C.-Y. Chiang, L.-J. Li, Small 10, 895-900 (2013)

15. G. Huang, T. Chen, Z. Wang, K. Chang, W. Chen, J. Power Sources 235, 122-128 (2013)

16. X.F. Qian, X.M. Zhang, C. Wang, Y. Xie, Y.T. Qian, Inorg. Chem. 38 , 2621-2623 (1999)

17. C. Zhao, D. Li, Y. Feng, J. Mater. Chem. A 1, 5741-5746 (2013)

18. Z.-D. Meng, K. Ullah, L. Zhu, S. Ye, W.-C. Oh, Mater. Sci. Semicond. Process. 27, 173-180 (2014)

19. J. Xie, S. Liu, G. Cao, T. Zhu, X. Zhao, Nano Energy 2, 49-56 (2013)

20. B. Qiu, X. Zhao, D. Xia, J. Alloys Compd. 579, 372-376 (2013)

21. S. Peng, L. Li, X. Han, W. Sun, M. Srinivasan, S.G. Mhaisalkar, F. Cheng, Q. Yan, J. Chen, S. Ramakrishna, Angew. Chem. Int. Ed. 53, 12594-12599 (2014)

22. J. Panpranot, S. Kaewkun, P. Praserthdam, J. Goodwin Jr, Catal. Lett. 91 95-102 (2003)

23. F. Haga, T. Nakajima, K. Yamashita, S. Mishima, React. Kinet. Catal. Lett. 63 253-259 (1998)

24. X. Jiang, Y. Ma, J. Li, Q. Fan, W. Huang, J. Phys. Chem. C 114, 22462-22465 (2010)

25. D. Kang, J.Y. Kwon, H. Cho, J.-H. Sim, H.S. Hwang, C.S. Kim, Y.J. Kim, R.S. Ruoff, H.S. Shin, ACS Nano 6, 7763-7769 (2012)

26. C.S. Rout, B.-H. Kim, X. Xu, J. Yang, H.Y. Jeong, D. Odkhuu, N. Park, J. Cho, H.S. Shin, J. Am. Chem. Soc. 135, 8720-8725 (2013)

27. S.G. Lyapin, A.N. Utyuzh, A.E. Petrova, A.P. Novikov, T.A. Lograsso, S.M. Stishov, J. Phys. Condens. Matter 26, 396001 (2014)

28. B.J. Tufts, I.L. Abrahams, C.E. Caley, S.R. Lunt, G.M. Miskelly, M.J. Sailor, P.G. Santangelo, N.S. Lewis, A.L. Roe, K.O. Hodgson, J. Am. Chem. Soc. 112, 5123-5136 (1990)

29. A.G. SchaufuB, H.W. Nesbitt, I. Kartio, K. Laajalehto, G.M. Bancroft, R. Szargan, Surf. Sci. 411, 321-328 (1998)

\section{Submit your manuscript to a SpringerOpen ${ }^{\odot}$ journal and benefit from:}

- Convenient online submission

- Rigorous peer review

- Immediate publication on acceptance

Open access: articles freely available online

- High visibility within the field

- Retaining the copyright to your article

Submit your next manuscript at springeropen.com 